\title{
Haematoma block or Bier's block for Colles' fracture reduction in the accident and emergency department - which is best?
}

\author{
J M Kendall, P Allen, P Younge, S M Meek, S E McCabe
}

\begin{abstract}
Objective-To offer clear guidance on the anaesthetic management of Colles' fractures in the accident and emergency (A\&E) department in the light of the conflict between existing reports and current trends, and to address the issue of alkalinisation of haematoma blocks.

Methods-This was a two centre, prospective, randomised clinical trial with consecutive recruitment of adult patients with Colles' fractures requiring manipulation to receive either Bier's block or haematoma block. There was subsequent blinded randomisation to alkalinised or non-alkalinised haematoma block.

Results -72 patients were recruited into the Bier's block group, and 70 into the haematoma block group. Bier's block was less painful to give than the haematoma block (median pain score $2.8 v 5.3 ; \mathrm{P}<0.001$ ), and fracture manipulation was also less painful in the Bier's block group (median pain score $1.5 v 3.0 ; \mathbf{P}<0.01)$. There was no significant difference in overall A\&E transit time between the two groups. There was better initial radiological outcome in terms of dorsal angulation in the Bier's block group $\left(-3.6^{\circ} \vee 2.1^{\circ} ; \mathbf{P}=0.003\right)$. More remanipulations were required in the haematoma block group (17/70 $v$ 4/72; $\mathbf{P}=0.003)$. There was a trend towards decreased pain on administration of the alkalinised haematoma block when compared with non-allalinised haematoma block, but this did not reach significance. There was no difference in pain score on fracture manipulation. There were no complications in either group.

Conclusions-Bier's block is superior to haematoma block in terms of efficacy, radiological result, and remanipulation rate; transit times are equal, both procedures are practical in the A\&E environment, and there were no complications. Bier's block is the anaesthetic management of choice for Colles' fractures requiring manipulation within the $A \& E$ department.

(F Accid Emerg Med 1997;14:352-356)
\end{abstract}

Keywords: Colles' fracture; Bier's block; haematoma block; alkalinisation

Colles' fractures are manipulated using a variety of anaesthetic techniques within the accident and emergency (A\&E) department. A survey of the larger A\&E departments in $1994^{1}$ showed that haematoma block had increased dramatically in popularity over the preceding five years, largely at the expense of the general anaesthetic, accounting for $33 \%$ of all reductions; a further $33 \%$ were performed under Bier's block, a proportion which had remained unchanged over the preceding five years. ${ }^{2}$ This move away from the use of a general anaesthetic may have been driven by the cost and resource implications of not having to admit patients and prepare them for a formal theatre procedure.

It is less clear why the haematoma block, rather than Bier's block, has filled the space left by the general anaesthetic when one reviews the available reports. Case ${ }^{3}$ retrospectively compared haematoma block, Bier's block, and general anaesthetic in 136 patients and found that there was no difference in the remanipulation rates between the three methods of anaesthesia. No other outcome measures were measured. She concluded that the haematoma block was the simplest procedure to perform in the A\&E department. Cobb and Houghton ${ }^{4}$ prospectively compared haematoma block and Bier's block in 83 patients and reported that the haematoma block was simpler and quicker to perform, but was inferior in efficacy. Wardrope et at prospectively compared haematoma block and Bier's block in 79 patients and found Bier's block to be superior in terms of analgesia, remanipulation rate, and radiological outcome. Abbazadegan and Jonsson ${ }^{6}$ also reported the superiority of Bier's block in terms of reduced pain during fracture manipulation and better radiological outcome, in a prospective study of 99 patients. The sharp rise in the popularity of the haematoma block therefore seems to be contradictory to the available evidence.

It may be that the haematoma block is preferred for its convenience because a single 
doctor can perform the entire procedure, while Bier's block is surrounded by preconceptions that discourage its use in the A\&E department: the need for an anaesthetist, the overall time of the procedure, and the possibility of complications due to cuff failure. However, $54 \%$ of $A \& E$ departments do not call anaesthetists to perform their Bier's blocks, and $40 \%$ do not starve their patients. ${ }^{1}$ There have been no reports of significant adverse effects with the universal use of prilocaine. ${ }^{78}$

Are anaesthetists necessary? Does Bier's block take longer overall? And is it safe in the A\&E department? None of the studies to date address all the issues of practical importance within the $A \& E$ department (that is, safety, efficacy, practicality, and patient transit time). We have performed the present study to address these issues and to offer some clearer guidance for the anaesthetic management of Colles' fractures within the A\&E department.

There is much current debate over the question of buffering local anaesthetic agents to improve their efficacy and shorten their duration of onset of action ${ }^{910}$; this question has not yet been extended to the haematoma block, and this was a further issue we attempted to address in this study by comparing alkalinised with non-alkalinised haematoma block.

\section{Methods}

STUDY DESIGN

This was a two centre, prospective, randomised clinical trial with consecutive recruitment of adult patients (over the age of 16 years) with Colles' fractures requiring manipulation. Within the haematoma block arm of the study, patients were further randomised to receive either alkalinised or non-alkalinised local anaesthetic, blinded to the attending physician.

The two centres involved were Gloucester Royal Hospital and Bristol Frenchay Hospital, and recruitment occurred between May 1994 and September 1995.

\section{PROCEDURES}

Ethical approval was received from the ethics committees at both Gloucester Royal NHS Trust and Frenchay NHS Trust.

Consecutive adult patients with Colles' fractures were recruited into the trial if they fulfilled the inclusion criteria for manipulation: $>15^{\circ}$ dorsal angulation, $>2 \mathrm{~mm}$ radial shortening. Informed consent was obtained from the patient.

Patients were randomised (by computer generated random numbers) to receive either Bier's block or haematoma block, and within the haematoma block leg of the study to receive either alkalinised or non-alkalinised lignocaine; the latter randomisation was blinded, the code being held by the respective pharmacy departments.

Instructions for both the haematoma block and Bier's block were laminated and displayed for the attending doctor to follow.

Haematoma block was performed using a conventional technique. ${ }^{11}$ The randomised haematoma block materials came preprepared from pharmacy and contained $1 \%$ lignocaine
Table 1 Demographic details

\begin{tabular}{lll}
\hline & $\begin{array}{l}\text { Bier's block } \\
(n=72)\end{array}$ & $\begin{array}{l}\text { Haematoma } \\
\text { block }(n=70)\end{array}$ \\
\hline $\begin{array}{l}\text { Mean age (years) } \\
\text { Female }\end{array}$ & 65 & 61 \\
$\begin{array}{l}\text { Fracture of dominant hand } \\
\text { Frykman type (mode and }\end{array}$ & $30(42 \%)$ & $61(87 \%)$ \\
$\begin{array}{l}\text { median) } \\
\text { Median pain score }\end{array}$ & $25(36 \%)$ \\
\hline
\end{tabular}

and either sodium bicarbonate or sodium chloride as the diluent; $8.8 \mathrm{ml}$ of lignocaine was mixed with $1.2 \mathrm{ml}$ of diluent to constitute a 10 $\mathrm{ml}$ volume haematoma block.

Bier's block was performed using a conventional technique. ${ }^{12}$ Prilocaine $0.5 \%$ was used in all cases, the volume being calculated on the basis of the patient's weight. An anaesthetist was not required for the performance of Bier's block, although there were two doctors present in the department during the procedure.

Manipulation of the fracture then followed. This involved distraction of the fracture followed by palmar flexion and ulnar deviation, and the forearm was placed in an incomplete Colles' plaster backslab. The patient was then sent for check radiography to ensure adequacy of reduction. The same criteria (as for the initial manipulation) were used to determine whether remanipulation was necessary. The patients were all followed up the following day in the fracture clinic for completion of plaster and orthopaedic review.

Ongoing care during follow up was received from the orthopaedic teams in the fracture clinics.

All information was collected prospectively on an appropriate proforma. Demographic data were collected at initial presentation (age, sex, side of fracture, mechanism of injury, Frykman classification of fracture, ${ }^{13}$ etc). The time of patient presentation, examination, anaesthetic administration, manipulation, and discharge were all recorded. Pain scoring was

\section{Table 2 Median pain scores}

\begin{tabular}{llll}
\hline & $\begin{array}{l}\text { Bier's block } \\
(n=72)\end{array}$ & $\begin{array}{l}\text { Haematoma } \\
\text { block }(n=70)\end{array}$ & P value \\
\hline $\begin{array}{l}\text { Presentation } \\
\begin{array}{c}\text { Administration of } \\
\text { anaesthetic }\end{array}\end{array}$ & 5.7 & 5.7 & $\mathrm{NS}$ \\
$\begin{array}{c}\text { Manipulation of } \\
\text { fracture }\end{array}$ & 2.8 & 5.3 & $<<0.001$ \\
$\begin{array}{c}\text { 30 Minutes after } \\
\text { manipulation }\end{array}$ & 1.5 & 3.0 & $<0.01$ \\
\hline
\end{tabular}

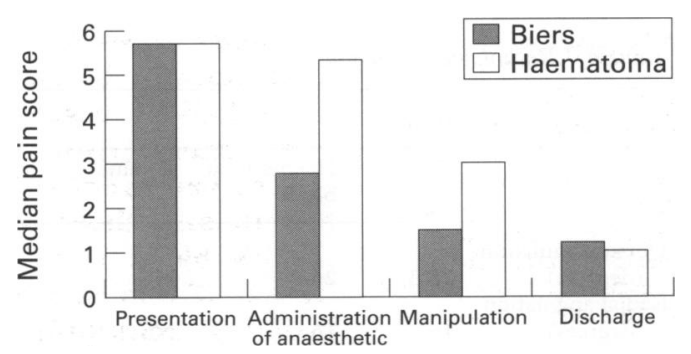

Figure 1 Median pain scores. Data points on the graph were taken from table 2. 
performed using visual analogue scales $^{14}$ and was assessed at presentation, on anaesthetic administration, on fracture manipulation (at the point of palmar flexion), and 30 minutes after manipulation. Complications were recorded, and whether immediate remanipulation within the A\&E department was required was also noted. Radiological examination occurred before and after manipulation, allowing measurement of dorsal angulation, radial tilt, and radial shortening before and after initial manipulation.

Results were analysed statistically by the research support unit at Frenchay NHS Trust.: Mann-Whitney $U$ tests were used for nonparametric data, $t$ tests for normally distributed data, and $\chi^{2}$ tests with continuity correction for data expressed as proportions.

\section{Results}

One hundred and fifty patients were recruited into the study, for whom data collection was complete in 142 (95\%). Seventy two were recruited into the Bier's block group, and 70 into the haematoma block group.

There were no significant demographic differences between the two groups (table 1). There was no difference in pain score on presentation or on discharge between the two groups (table 2 and fig 1), but Bier's block was less painful to give than the haematoma block $(P<<0.001)$, and manipulation of the fracture was less painful in the Bier's block group $(\mathrm{P}<$ 0.01 ).

There was no difference in the overall transit time through the $A \& E$ department between the two groups; when the components of that time were broken down (table 3 ) the only difference in timings that reached significance was the time between the examination of the patient and the administration of the anaesthetic; in this time window, Bier's block took longer $(P<0.001)$.

Table 3 Median timings (minutes)

\begin{tabular}{llll}
\hline & $\begin{array}{c}\text { Bier's block } \\
(n=72)\end{array}$ & $\begin{array}{l}\text { Haematoma } \\
\text { block }(n=70)\end{array}$ & P value \\
\hline $\begin{array}{c}\text { Presentation to } \\
\text { examination }\end{array}$ & 29 & 24 & NS \\
$\begin{array}{c}\text { Examination to } \\
\text { administration }\end{array}$ & 88 & 65 & $<0.001$ \\
$\begin{array}{c}\text { Administration to } \\
\text { manipulation }\end{array}$ & 10 & 15 & NS \\
$\begin{array}{c}\text { Manipulation to } \\
\text { discharge }\end{array}$ & 53 & 55 & NS \\
$\begin{array}{c}\text { Total time in } \\
\text { department }\end{array}$ & 199 & 190 & NS \\
\hline
\end{tabular}

Table 4 Radiological outcome

\begin{tabular}{llllllll}
\hline & Initial & & & & Post-manipulation & \\
\hline & $\begin{array}{c}\text { Bier's } \\
\text { block }\end{array}$ & $\begin{array}{l}\text { Haematoma } \\
\text { block }\end{array}$ & P value & & $\begin{array}{c}\text { Bier's } \\
\text { block }\end{array}$ & $\begin{array}{l}\text { Haematoma } \\
\text { block }\end{array}$ & P value \\
\hline $\begin{array}{c}\text { Dorsal angulation } \\
\text { (degrees) }\end{array}$ & 26.3 & 26.9 & NS & & -3.6 & 2.1 & 0.003 \\
$\begin{array}{c}\text { Radial angulation } \\
\text { (degrees) }\end{array}$ & 16 & 16 & NS & & 22 & 22 & NS \\
$\begin{array}{c}\text { Radial shortening } \\
(\mathrm{mm})\end{array}$ & 2.5 & 3.0 & NS & & 0 & 1.0 & NS \\
\hline
\end{tabular}

Table 5 Alkalinised versus non-alkalinised haematoma block

\begin{tabular}{llll}
\hline & Alkalinised & Non-alkalinised & P value \\
\hline $\begin{array}{c}\text { Median pain score } \\
\text { on administration }\end{array}$ & 4.4 & 5.9 & NS \\
$\begin{array}{c}\text { Median pain score } \\
\text { on manipulation }\end{array}$ & 3.5 & 3.0 & NS \\
\hline
\end{tabular}

There was a better radiological outcome (table 4) in terms of dorsal angulation in the Bier's block group $(P=0.003)$; there was no significant difference in radiological outcome in radial tilt and radial shortening.

There were more remanipulations in the haematoma block group (17/70) than in the Bier's block group (4/72) $(P=0.003)$.

There was a trend towards decreased pain on administration of the alkalinised haematoma block compared with the nonalkalinised block (table 5), but this did not reach significance $(P=0.08)$. There was no difference in pain on manipulation of the fracture between the alkalinised and the nonalkalinised haematoma block.

No significant complications were reported in either group.

\section{Discussion}

The type of anaesthetic used for the manipulation of Colles' fractures has undergone a significant change in favour of the haematoma block at the expense of the general anaesthetic over the last five years. ${ }^{12}$ It is easy to understand the driving forces behind the move from general anaesthesia to local or regional anaesthesia, bearing in mind the financial implications of admitting patients. It is much less clear why this change has not been in favour of Bier's block rather than the haematoma block, if one takes into account the available evidence. ${ }^{4-6}$ It may be because of a combination of firmly entrenched personal preference or simply because of previous experience and training, or perhaps because none of the previous reports have prospectively taken into account, in a single study, all of the factors that are of practical importance within a busy $A \& E$ department. It may be that long held preconceptions regarding Bier's block still discourage its use in the $A \& E$ environment. We have addressed these issues in our study and we support the findings of previous work. We have shown that Bier's block is more effective than the haematoma block in terms of pain relief, and that Bier's block gives a better radiological result and a lower early remanipulation rate (that is, due to inadequate initial reduction, before discharge from $A \& E$ ). Furthermore, there are no negative implications in terms of patient transit times through the $\mathrm{A} \& \mathrm{E}$ department, and it is not necessary to call an anaesthetist specifically to perform the procedure. In short, Bier's block is a safe, effective, and practical procedure, superior to the haematoma block in all our outcome measures.

Pain scores were measured by the patient at various points during the procedure using 
linear visual analogue scales. It is reassuring to observe a downward trend in the pain scores in both groups from presentation to discharge; indeed, at the point of presentation and on discharge there was no significant difference between the two groups. The pain on administration of the anaesthetic and on manipulation of the fracture, however, was significantly less in the Bier's block group. A possible contributing factor to this may be more interoperator variability within the haematoma block group (although we have no evidence for this). The correct technique - which has a definite learning curve- to give a haematoma block safely and effectively is vital, otherwise it will not provide adequate anaesthesia and it may introduce infection into the fracture site. Venepuncture is the only practical skill that is required to perform a successful Bier's block and this is easier for an A\&E senior house officer than local fracture site infiltration. Our study has confirmed present trends, ${ }^{1}$ and previous reports, ${ }^{78}$ that Bier's block seems to be safe and can be performed by appropriately trained A\&E staff without an anaesthetist present; with this in mind, it is important that we select the procedure that is most easily adopted and most reproducible, considering the rapid turnover of junior $\mathrm{A} \& \mathrm{E}$ staff.

We encountered no adverse events in either group during the study. There is a theoretical risk of introducing infection during fracture site infiltration with local anaesthetic while performing a haematoma block; we encountered no such complication, which is consistent with previously reported studies. ${ }^{11}$ We also encountered no complications attributable to systemic anaesthetic toxicity in any patient, which is also consistent with the available reports. ${ }^{315}$ Both procedures seem safe to perform, assuming that adequate precautions are observed. We did not specifically starve patients before Bier's block, consistent with practice in other departments. ${ }^{1}$ Full resuscitation facilities must be available for both types of anaesthesia. More didactic statements of safety cannot be made since a full assessment of risk would require a much greater sample to encounter the small potential risk with either procedure.

Two doctors are required in the $A \& E$ department while a Bier's block is being performed; the second is not necessary to help perform the Bier's block itself, but to be available in the unlikely event of a serious adverse reaction. In certain circumstances (for example at night, or during a snow/ice period), the lack of manpower may require the use of the haematoma block as an alternative. It must be noted, however, that Colles' fractures do not tend to present late at night when there may be only one junior $A \& E$ doctor on duty, and when they do it would be reasonable to delay reduction until the following morning (having splinted the fracture and given analgesia).

There was no significant difference between the two groups in terms of total transit time through the $A \& E$ department. It is a commonly held misconception that the Bier's block results in undue delays, and this probably has its origin from the perceived necessity to call and wait for an anaesthetist to administer the block. When the time flow profile of a patient through the various stages of management of a Colles' fracture is broken down, it is very similar between the two groups. At only one stage was there a significant difference, and this was between examination of the patient and the administration of the anaesthetic, when it was found that the Bier's block took longer. It is unclear why this was the case, but it may reflect the fact that it takes slightly longer to set up a Bier's block (the patient's blood pressure needs to be measured, the cuff needs to be checked, a Venflon needs to be inserted into the unaffected arm, and so on). The most important time as far as the patient and the department is concerned is the total transit time from presentation to discharge, and this was found to be essentially the same, at just over three hours in both groups.

There were significantly more early remanipulations in the haematoma block group (that is, performed before discharge from the A\&E department) because of inadequate initial reduction. This is because the anaesthetic efficacy is inferior to the Bier's block, and therefore the patient is in more pain, is less relaxed, and satisfactory reduction becomes more difficult.

The patients are all being followed up in the medium term with ongoing data collection to assess any differences in outcome in terms of function, ongoing pain, and residual deformity (both clinical and radiological).

Debate continues with respect to the effect of the alkalinisation of local anaesthetics to reduce their pain on injection, increase their efficacy, and reduce the time to onset of action. ${ }^{910}$ There are no reported studies to date addressing this issue in haematoma blocks. We therefore divided our haematoma block group to receive either alkalinised or plain lignocaine, and this was randomised and blinded to the attending physician. There was a tendency towards decreased pain on administration of the alkalinised haematoma block, but this did not reach significance with the numbers in our study, and alkalinised haematoma block was still significantly more painful to give than Bier's block. There was no difference in median pain scores on manipulation of the fracture. It may be that with larger numbers in this part of the study we could have shown that alkalinising the haematoma block is useful.

\section{CONCLUSION}

Bier's block is superior in terms of efficacy, radiological result, and remanipulation rate when compared to the haematoma block in the anaesthetic management of a Colles' fracture in the $A \& E$ department; preconceptions regarding transit time delays with the Bier's block are unfounded, and our study agrees with other reports that the procedure appears to be safe and practical when performed by $A \& E$ staff in a suitable environment with appropriate resuscitation facilities. Bier's block should therefore be used as the anaesthetic of choice 
in the manipulation of Colles' fractures in the A\&E department. Our study did not identify any significant benefit in alkalinising the haematoma block.

We would like to thank Catherine Waters of the Research Support Unit at Frenchay NHS Trust for her advice and statistical support.

1 Kendall JM, Allen PE, McCabe SE. A tide of change in the management of an old fracture? J Accid Emerg Med 1995;12:187-8.

2 Hunter JB, Scott MJ, Harries SA. Methods of anaesthesia used for reduction of Colles' fractures. BMJ 1989;299: 1316-7.

Case RD. Haematoma block-a safe method of reducing Colles' fractures. Injury 1985;16:469-70.

4 Cobb AG, Houghton GR. Local anaesthetic infiltration versus Bier's block for Colles' fractures. BMJ 1985;291: 1683-4.

5 Wardrope J, Flowers M, Wilson DH. Comparison of local anaesthetic techniques in the reduction of Colles' fractures. Arch Emerg Med 1985;2:67-72.
6 Abbaszadegan H, Jonsson U. Regional anaesthesia preferable for Colles' fracture. A controlled comparison with able for Colles fracture. A controlled 190:61:348-9.

7 Bocal anasthes $\mathrm{K}$, Sloan JP. Prilocaine for Bier's block: how safe is safe? Arch Emerg Med 1990;7:189-95.

safe is safe? Arch Emerg Med 1990;7:189-95.
Brown EM, McGriff JT, Malinowski RW. Intravenous regional anaesthesia (Bier's block): review of 20 years experience. Can J Anaesth 1989;36:307-10.

9 Christoph RA, Buchanan L, Begalla K, Schwartz S. Pain reduction in local anaesthetic administration through $\mathrm{pH}$ buffering. Ann Emerg Med 1988;17:117-20.

10 Mcglone $R$, Bodenham A. Reducing the pain of intradermal lignocaine injection by $\mathrm{pH}$ buffering. Arch Emerg Med 1990;7:65-8.

11 Johnson P, Noffsinger M. Haematoma block of distal forearm fractures. Is it safe? Orthop Rev 1991;11:977-9.

12 Quinton DN. Regional anaesthesia for hand surgery in accident and emergency. Hosp Update 1989;Nov:827-35.

13 Frykman G. Fracture of the distal radius including sequelae. Acta Orthop Scand (suppl);108:1967.

14 Huskisson FC. Graphic representation of pain. Pain 1976;2:175-84.

15 Quinton DN. Local anaesthetic toxicity of haematoma blocks in the manipulation of Colles' fractures. Injury $1988 ; 19: 239-40$.

\section{Journal of Accident and Emergency Medicine- http://www.jnlaem.com}

Visitors to the world wide web can now access the Journal of Accident and Emergency Medicine either through the BMJ Publishing Group's home page (http://www.bmjpg.com) or directly by using its individual URL (http://www.jnlaem.com). There they will find the following:

- Current contents list for the journal

- Contents lists of previous issues

- Members of the editorial board

- Subscribers' information

- Instructions for authors

- Details of reprint services.

A hotlink gives access to:

- BMJ Publishing Group home page

- British Medical Association web site

- On line books catalogue

- BMJ Publishing Group books

The web site is at a preliminary stage and there are plans to develop it into a more sophisticated site. Suggestions from visitors about features they would like to see are welcomed. They can be left via the opening page of the BMJ Publishing Group site or, alternatively, via the journal page, through "about this site". 